\title{
Molecular detection of Methylotrophs from an Indian landfill site and their potential for biofuel production
}

\author{
Yadava S. ${ }^{1, *}$ and Maitra S.S. ${ }^{2}$ \\ 1Department of Biotechnology, Assam University, Silchar, PIN-788011 \\ ${ }^{2}$ School of Biotechnology, Jawaharlal Nehru University, New Delhi, PIN-110067 \\ Received: 09/06/2017, Accepted: 19/09/2017, Available online: 24/10/2017 \\ *to whom all correspondence should be addressed: e-mail: shailendrayadav2@gmail.com
}

\begin{abstract}
Emission of $\mathrm{CH}_{4}$ from landfills is a major cause of concern as $\mathrm{CH}_{4}$ is twenty four times more potent than $\mathrm{CO}_{2}$, as a greenhouse gas. However, landfills also harbor a group of bacteria called methanotrophs, which can oxidize $\mathrm{CH}_{4}$. They can be used for in situ bioremediation to reduce methane emissions. They can also be used for production of methanol or renewable diesel, utilizing methane in natural gas or biogas. Methanotrophs are a subgroup of methylotrophs. We used molecular techniques for detection of methylotrophs in samples from a landfill in New Delhi. We could detect five methylotrophs. Isolation and efficiency in methanotrophy of these bacteria is undergoing now.
\end{abstract}

Keywords: Methylotrophs, Molecular detection, Municipal Solid Waste leachate

\section{Introduction}

Climate change is one of the most important challenges that the humankind is facing in this era. It is related to forest and land degradation, freshwater shortage, food security and air-water pollution. According to Intergovernmental Panel on Climate Change (IPCC) report, the global mean temperature may increase between 1.4 to $5.8^{\circ} \mathrm{C}$ by 2100 (Mitigation, 2011). The impact of this rise in temperature would be particularly severe, in the tropical areas, which mainly consist of developing countries including India. The climate change issue for developing countries is correlated with pace of sustainable development (Sathaye et al. 2006). At present India's requires plans for sustainable development and she must address many climate change concerns. These conscious policy decisions may prove helpful for obtaining climatefriendly sustainable development model (Sharma et al. 2006; Kumar et al. 2009).

Municipal Solid Waste (MSW) management has remained one of the most neglected areas of the municipal service delivery in Delhi, India. About $70-80 \%$ of generated MSW is collected, $9 \%$ of which is treated through composting and rest is disposed in uncontrolled open landfills. In absence of leachate and landfill gas collection systems, these landfills are a major source of groundwater contamination and generation of greenhouse gases like methane (Yadav et al., 2015). Methane is an important greenhouse gas, because it is 25 times more potent than $\mathrm{CO}_{2}$ in global warming (Yadav et al., 2014). Despite directives from the Honorable Supreme Court and the MSW Rules 2000 of Government of India, Municipal Corporation of Delhi has so far failed to address the issue of Landfill Gas(LFG) recovery (mixture of $\mathrm{CO}_{2}, \mathrm{CH}_{4}$ gas): which is causing great harm to environment and leading to loss of a potential source of energy (Talyan et al., 2008; Talyan et al., 2007).

Access to clean, affordable and reliable energy has been a major requirement of the world's increasing population and economic growth. Our use of energy in the twenty-first century must be sustainable. Solar and water-based energy generation and engineering of microbes to produce biofuels, are a few examples of alternatives (Chu and Majumdar, 2012).

Diminishing oil reserves and climate-changing greenhouse gas emissions have led to calls for clean and renewable liquid fuels (Hu et al. 2016). Currently, India contributes about $5 \%$ of total global $\mathrm{CO}_{2}$ emissions. To prevent $\mathrm{CO}_{2}$ emissions to peak quickly, part of India's new energy needs must come from low-carbon technologies. However, India had only $60 \mathrm{GW}$ of low-carbon capacity installed by the end of 2014, and only $3 \mathrm{GW}$ of solar power. A more robust electrical grid and a dramatic rise in renewable energy sources are required to achieve the target (Jackson et al., 2015).

Methane $\left(\mathrm{CH}_{4}\right)$ is the second most important atmospheric greenhouse gas after $\mathrm{CO}_{2}$ (Cai et al. 2016) and is believed to account for $17 \%$ of global warming (Collins et al. 2013). Although most sources and sinks of methane have been identified, their relative contributions to atmospheric methane levels are uncertain (Houghton et al., 2001; YvonDurocher et al., 2014; Bridgham et al., 2013; Kirschke et al., 2013). About 500-600 Tg of methane is emitted annually to the atmosphere of which $74 \%$ is biogenic (Solomon 2007; Jackson et al., 2015).

Landfill sites are among the largest anthropogenic source of methane. It constitutes 30 and $24 \%$ of the anthropogenic $\mathrm{CH}_{4}$ production in Europe and the US, respectively 
(Solomon, 2007; Mitigation, 2011). In comparison to the western countries, the composition of organic waste in municipal solid waste (MSW) of developing countries like India has been higher (40\% - 60\%). This gives it more potential to emit higher GHGs from per ton of MSW compared to the developed world (Mayumi et al., 2013). Moreover, landfills in India are neither planned nor engineered. They are often found in low-lying open areas, where municipal waste is haphazardly and indiscriminately disposed. These sites neither have landfill lining to avoid percolation of leachate to groundwater table nor leachate collection facility (Yadav et al., 2015). The city of New Delhi generates about 9000 tons of solid waste per day (Gupta et al., 2007). Due to scarcity of land in big cities, municipal authorities are using same landfill for nearly 10 - 20 years. Thus, the possibility of anaerobic digestion of MSW and emission of greenhouse gas (GHGs) further increase (Rawat and Ramanathan, 2011).

Microbial decomposition, climatic conditions, refuse characteristics and land-filling operations are among the many factors that contribute to the generation of methane (Talyan et al., 2007; Bridgham et al., 2013). The migration of gas and leachate away from the landfill boundaries and their release into the surrounding environment presents serious environmental concerns (Hansen et al., 1998; Bloom et al., 2010; Singh and Mittal, 2011). Leachate harbors huge prokaryotic diversity, which yet remains to be discovered. Characterizing microbial diversity of that mediates carbon and methane flux in landfills, is critical for predicting their role and responses to climate changes (Bardgett and van der Putten, 2014).

Methanotrophs use methane as their sole carbon source and directly convert methane into cellular compounds or transform it into a substrate that drives processes via interaction with other microbes. The biological conversion of methane has become a topic of intense interest. In 2013 the Advanced Research Projects Agency (ARPA-E) , within the U.S. Department of Energy, granted US \$34 million worth of funding directed toward research for converting methane into liquid fuels (Strong et al., 2015). Bacteria like Methylosinus trichosporium, have the capacity to oxidize methane. However, processes for microbial conversion of methane to biodiesel are marred by low productivity, slow growth rate and undesirable substances in the lipid accumulated by the bacteria. Therefore, there is need for bio-prospecting for a better methanotroph.

In the present study, a PCR based study was performed for detection and community fingerprinting of methylotrophs present in the MSW leachate from a landfill site of Delhi, India, targeting 16S rDNA sequences with methylotroph specific primers.

\section{Materials and Methods}

\subsection{Sampling}

Samples were collected from the Ghazipur landfill site of Delhi. It is situated in east Delhi and is the oldest and largest landfill of Delhi. It was established in the year 1984 and spans 29.6 hectares in area. It has received about 2200 TPD waste till now. The GPS location of sampling point was $28^{\circ} 37^{\prime} 22.4^{\prime \prime} \mathrm{N}-77^{\circ} 19^{\prime \prime} 25.7^{\prime \prime} \mathrm{E}$ and the $\mathrm{pH}$ of the sample was in between 7.4-8.4.

\subsection{Nucleic acid extraction, PCR amplification and cloning}

DNA from both landfill leachate samples was extracted on the same day of sampling, using Fast DNA Spin Kit for soil (MP Biomedicals, CA, USA). DNA from leachate was amplified using the universal primer set 27FWD and 1492REV. The amplification profile was $94{ }^{\circ} \mathrm{C}$ for $5 \mathrm{~min}, 94$ ${ }^{\circ} \mathrm{C}$ for 30 s for 30 cycles, $55^{\circ} \mathrm{C}$ for 1 minute, elongation at 72 ${ }^{\circ} \mathrm{C}$ for 2 minute and final extension at $72{ }^{\circ} \mathrm{C}$ for 10 minutes followed by a cooling step down to $4{ }^{\circ} \mathrm{C}$. 16S rDNA gene specific PCR products, thus obtained, were purified by PCR purification kit (Fermentas, UK) as recommended by manufacturer's protocol. PCR amplicons of 16S rDNA gene were cloned inside PTZ57R/T vector using the Insta-T/A cloning kit (Fermentas, UK) and transformed into Escherichia coli $\mathrm{DH} 5 \alpha$. The positive clones were selected using blue-white screening on Luria-Bertani plates containing Ampicillin $(100 \mathrm{mg} / \mathrm{ml})$, X-gal $(20 \mathrm{mg} / \mathrm{ml})$, and IPTG (100 mM). Then positive clones were sequenced using M13 FWD primer.

\subsection{DNA Sequencing and Phylogenetic Analysis of 165 rDNA clones}

Sequencing was performed for all the clones with the $A B I$ prism 3130 Genetic Analyzer (Applied Biosystem Inc., CA) at the Department of Biochemistry, South Campus, Delhi University. The sequences were edited to exclude the PCR primer-binding site and manually corrected with Sequence Scanner 1.0 (Applied Biosystems) and were checked further for vector contamination using the Vecscreen tool (http://www.ncbi.nlm.nih.gov/tools/vecscreen/).

The sequences showing similarity with vector sequences from both ends were trimmed. Sequences were then compared with the available nucleotide database from the NCBI GenBank using the BLAST program (Altschul et al., 1997). The partial nucleotide sequences of $16 \mathrm{~S}$ rDNA genes were submitted to $\mathrm{NCBI}$ under accession numbers KM041243 to KM041247 (Table 1). Partial 16S rDNA sequences obtained from this study were used for similarity search in NCBI database using BLAST program. After performing BLAST, sequences showing similarity above $90 \%$ were used and aligned in MEGA software version 6.0 (Tamura et al., 2013) using ClustalW. The phylogenetic relatedness among clones was estimated using the Maximum Likelihood Tree using Kimura K2P+G model with 2000 bootstrap value (Kimura, 1980). For model selection Bayesian analysis was performed and the model with lowest BIC value (i.e., i.e. 9109.105) was chosen for tree construction. All positions containing gaps and missing data were eliminated from the dataset (complete deletion option). The phylogenetic analysis was carried out using MEGA software version 6.0 (Tamura et al., 2013) (Figure 1).

\subsection{Denaturing Gradient Gel Electrophoresis}

For denaturing gradient gel electrophoresis, genomic DNA extracted from the landfill leachate was amplified using 
primer 27FWD and GC 968 which gave a product length of about $700 \mathrm{bp}$. DGGE was performed with a D-Code universal mutation detection system (Biorad, Hercules, CA, USA), using $16 \mathrm{~cm}$ by $16 \mathrm{~cm}$ and one mm gels. PCR products were loaded onto $7 \%(\mathrm{w} / \mathrm{v})$ polyacrylamide gels. The polyacrylamide gels (Bis-Acrylamide, 37.5:1) were made with denaturing gradients ranging from 40 to $60 \%$. $100 \%$ denaturant contained $7 \mathrm{M}$ urea and 40\% Formamide. Electrophoresis was initially run at $200 \mathrm{~V}$ for $10 \mathrm{~min}$ at $60^{\circ} \mathrm{C}$, and afterwards at $130 \mathrm{~V}$ for 4 hours. After electrophoresis, the gel was silver stained and scanned under white light using Gel doc (Biorad). DGGE gel was further analyzed using Gel2K software (Svein Norland, Department of BiologyUniversity of Bergen, Norway) (Figure 2).

Table 1. Methylotrophic 16S rDNA amplicon sequences with accession numbers submitted to NCBI.

\begin{tabular}{|c|c|c|c|c|c|}
\hline Sequence ID & Size & Accession no. & Location & Organism name & Closest relative \\
\hline METG2_16S rDNA & $701 \mathrm{Nt}$ & KM041243 & Ghazipur landfill & $\begin{array}{c}\text { Methylobacillus } \\
\text { flagellatus }\end{array}$ & $\begin{array}{c}\text { Methylobacillus } \\
\text { flagellatus }\end{array}$ \\
\hline METG3_16S rDNA & $705 \mathrm{Nt}$ & KM041244 & Ghazipur landfill & $\begin{array}{c}\text { Methylotenera } \\
\text { mobilis }\end{array}$ & $\begin{array}{c}\text { Methylobacillus } \\
\text { flagellatus }\end{array}$ \\
\hline METG4_16S rDNA & $719 \mathrm{Nt}$ & KM041245 & Ghazipur landfill & $\begin{array}{c}\text { Methylobacillus } \\
\text { gramineus }\end{array}$ & $\begin{array}{c}\text { Methylobacillus } \\
\text { flagellatus }\end{array}$ \\
\hline METG6_16S rDNA & $729 \mathrm{Nt}$ & KM041246 & Ghazipur landfill & $\begin{array}{c}\text { Methylobacillus } \\
\text { arboreus }\end{array}$ & $\begin{array}{c}\text { Methylobacillus } \\
\text { flagellatus }\end{array}$ \\
\hline METG7_16S rDNA & $637 \mathrm{Nt}$ & KM041247 & Ghazipur landfill & $\begin{array}{l}\text { Methylovorus } \\
\text { glucosetrophus }\end{array}$ & $\begin{array}{c}\text { Methylobacillus } \\
\text { flagellatus }\end{array}$ \\
\hline
\end{tabular}

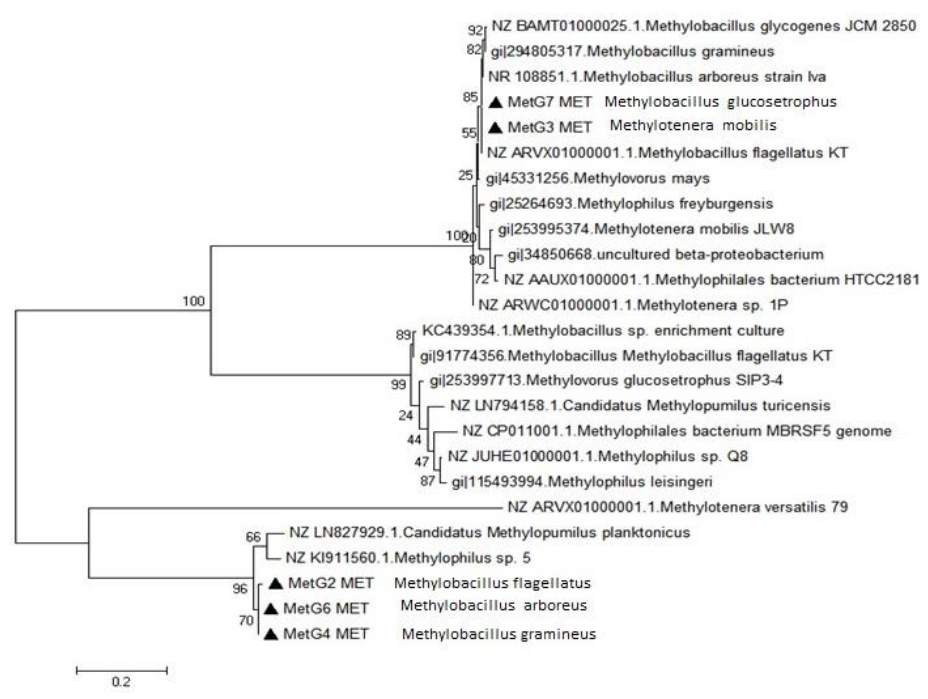

Figure 1. The phylogenetic relationship of 25 partial 16S rDNA sequences (the confirmed 5 sequences of clones generated in this study, recovered from Ghazipur landfill site Delhi, marked with black triangle) was inferred by the ML method using $\mathrm{K} 2 \mathrm{P}+\mathrm{G}$ parameter model with 2000 bootstrap replicates using the MEGA 6 tree building program

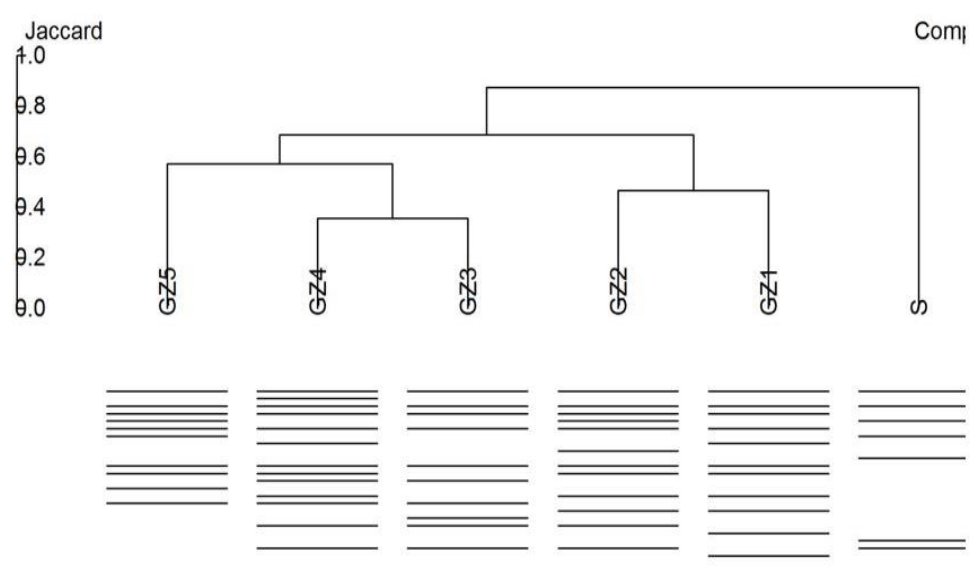

Figure 2. Showing Jaccard cluster analysis of methylotrophic community based on 16S rDNA amplicons from samples obtained from five locations of Ghazipur landfill site Delhi 


\section{Results and Discussion}

\subsection{Identification of methanotrophs present in landfill site} Delhi using 16S rDNA sequencing

Present study investigates presence of methylotrophs in landfill leachate of Ghazipur landfill site. To the best of our knowledge this is first study where molecular analysis of methylotrophs/methanotrophs have been performed and their presence reported from a Indian landfill site. Phylogenetic analysis of $16 \mathrm{~S}$ rDNA clones indicate the presence of methanotrophs belonging to the domain bacteria, phylum proteobacteria, order Methanophilales, genus methanobacillus in the Ghazipur landfill site of Delhi. Sequence METG2_16S_rDNA matched with Methylobacillus flagellatus strain belonging to order Methanophilales. METG3_16S_rDNA matched with Methylotenera mobilis. MET4_16S_rDNA matched with Methylobacillus gramineus and METG6_16_rDNA matched with Methylobacillus arboreus, which is a obligate methanol-utilizing Gram-negative, asporogenous, motile rod that occur singly, in pairs or in small groups. They oxidize methanol by PQQ-MDH to formaldehyde and assimilate it via the RuMP pathway (Gogleva et al., 2011). Sequence METG7_16S_rDNA matched with Methylovorus glucosetrophus. All them showed $99 \%$ to $96 \%$ similarity to Methylobacillus flagellatus. The family Methylophilaceae includes all four described genera (Methylophilus, Methylovorus, Methylobacillus and Methylotenera). All represent obligate or restrictive facultative methylotropy.

Methylobacillus flagellatus belongs to the Betaproteobacteria class and is most closely related. Methylobacillus flagellatus strain KT utilizes methanol and methylated amines as the sole sources of carbon and energy and is classified as an obligate methylotroph. The strain was isolated from a metropolitan sewer system and selected as a prospective industrial strain due to its high growth rates on methanol, high tolerance to methanol and formaldehyde, high biomass yield, and high coefficient of conversion of methanol into biomass (Baev et al., 1992; Chistoserdova et al., 2007). Methylotrophy is the metabolic capacity to grow on reduced carbon compounds such as methane, methanol, methylated amines, etc. Methylotrophy functions in Methylobacillus flagellatus, (Chistoserdova et al., 2007). This can also be a type I methanotroph belonging to gamma-proteobacteria.

Benstead et al. 1998, found that methanol promotes atmospheric methane oxidation by methanotrophic cultures and in soil. Methanol enhances activity of methanotrophic activity in soils by acting either as substrate for growth and source of energy production or as reducing agent that are required for the continued oxidation of atmospheric methane(Benstead et al., 1998; Hanson and Hanson, 1996). Eshinimaev et al. 2002 found that alkaliphilic methanotroph Methylomicrobium buryatense $5 \mathrm{~B}$ is capable of growing at high methanol concentrations (up to $1.75 \mathrm{M}$ ). They hypothesized that the high methanol tolerance of $M$. buryatense $5 B$ is due to the utilization of formaldehyde for the synthesis of sucrose, glycogen, and the glycoprotein and to the oxidation of excess reducing equivalents through the respiratory chain. Further in 2015, Gilman et al., found that this strain has both high growth rate and carbon conversion efficiency and emphasized on its use for commercial methane bioconversion to value-added products such as fuels and chemicals (Gilman et al., 2015).

\subsection{Diversity of Methylotropic Bacteria by Denaturing Gradient Gel Electrophoresis}

Abundance and diversity of methylotrophic bacteria were studied using denaturing gradient gel electrophoresis in leachate samples collected at five different locations at Ghazipur landfill site, Delhi. 16S rDNA gene amplicons used for cloning were analyzed on the DGGE gel for estimation of their richness in respective samples. Banding patterns of 16S rDNA amplicons obtained from all five leachate samples of the Ghazipur landfill site were compared using Gel 2K software and the analysis of DGGE image revealed the presence of total 23 bands Figure 2 .

There are some unique bands in each lane, which indicates the variation of methylotrophic community residing in those particular samples. Cluster analysis of bands using Jaccard analysis indicated the presence of two main clusters on the basis of number of similarity and DGGE bands in Figure 2. In first cluster samples GZ3, GZ4 and GZ5 sample clustered together showing similar community structure and diversity. In second cluster samples GZ1 and GZ2 of leachate clustered together. It indicates that methylotrophic community structure inhabiting in all five leachate samples were similar. In terms of richness regarding number of bands, GZ4 samples has maximum 13 bands followed by GZ2, GZ1, GZ2 and GZ5 having 12,11 and 10 bands respectively. Methylotrophic community diversity present in all five samples on the basis of band pattern were found to be uniform in the Ghazipur landfill site.

\subsection{Culture independent molecular analysis of Methylotrophs}

Methylotrophs/methanotrops have gained attention since last decades, as they have considerable potential for the oxidation of methane (Schimel, 2000; Singh, 2011). The slow growth rate of methanotrophs hinders their study by conventional culture dependent techniques. Methods such as the MPN technique, FISH can be biased by selective culture conditions or require too much manual effort. Therefore, PCR based molecular techniques are widely used for their identification and diversity analysis. Methanotrophs are extensively studied in a wide variety of environments like rice paddy fields, landfill cover soil etc. because of their critical role in the global carbon cycle and methane mitigation (Cai et al., 2016; Han et al., 2009; Singh, 2011; Su et al., 2014).

Culture-independent surveys showed that methanotrophs belonging to family Methylophilaceae are ubiquitous, thriving in a variety of natural as well as man-made environments. (Murrell et al., 1998; Chen et al., 2007; Han et al., 2009; Musenze et al., 2016; Lee et al., 2015; Su et al., 2014). In present study we used 16 S rDNA based cloning- 
sequencing and DGGE for identification and diversity analysis of methylotrophs/methanotrophs present in the leachate samples of Ghazipur, Delhi. Novel Type 1 obligate methanotrophs belonging to class gamma proteobacteria has been also found to be associated with leachate samples of Ghazipur landfill site which can utilize methane and formaldehyde as energy source (Chistoserdova et al., 2007; Gogleva et al., 2011).

\subsection{Methylotrophic potential for methane mitigation and biofuel production}

Technology for conversion of natural gas/landfill gas to liquid fuel is highly desirable. Current chemical conversion of natural gas to liquid fuels is not economically competitive. Bioconversion is a promising alternative because of high specificity and high process energy efficiency under very mild conditions. Biotechnology aims to provide sustainable solutions for the provision of fuels, chemicals and materials (Nielsen et al., 2014). Global climate change linked to the accumulation of greenhouse gases has caused concerns regarding the use of fossil fuels as the major energy source. To mitigate climate change while keeping energy supply sustainable, one solution is to rely on the ability of microorganisms to use renewable resources for biofuel synthesis (Liao et al., 2016; Singh, 2011). To reduce or avoid collateral emissions, raw materials for sustainable biofuel production should come from atmospheric $\mathrm{CO}_{2}$ or from carbon that is otherwise released as GHGs, without being efficiently utilized (Strong et al., 2015).

As methane is a more potent $\mathrm{GHG}$ than $\mathrm{CO}_{2}$ (Yvon-Durocher et al., 2014), there is increasing pressure to find ways of more efficient use of methane as a carbon source. Methane produced from landfill or by anaerobic digestion of various organic wastes or from "stranded natural gas" can be exploited as feeds for production of alternate biofuel (Conrado and Gonzalez, 2014; Peralta-Yahya et al., 2012). New technologies for effective conversion of flared/waste sources of methane into chemical compounds, including next-generation fuels, have become active matter of research. (Kalyuzhnaya et al., 2013). In literature, there is report that Methylotrophus capsulatus, Methylosinus trichosporium can convert methane and oxygen to methanol (Hwang et al., 2014).

Microbial methane oxidation acts as the only known biological sink of methane, as methanotrophs limit the release of methane from many methanogenic areas. Methanotrophs represent a potential biological platform for methane-based biocatalysis.

16S rDNA sequencing revealed presence of Methylobacillus flagellatus strain KT in Ghazipur landfill site, Delhi. It utilizes methanol and methylated amines as the sole source of carbon and energy. Because of its higher growth rate, tolerance to methanol and high coefficient of conversion of methanol into biomass can be utilized in scale up process for production of methanol (alternate biofuel) using MSW leachate as renewable energy source.

\section{Conclusion}

Methanotrophs are a special group of bacteria within methylotrophs. Methanotrophs can survive on methane as sole carbon source for both growth and energy generation. We have identified a few methylotrophs. Research is continuing for their isolation. Study is being done whether they could survive on methane alone. If that is case, they qualify for being methanotrophs as well.

\section{Acknowledgment}

Dr. S. S. Maitra is grateful to the Department of Science and Technology (DST), Government of India( under PURSE program) and Jawaharlal Nehru University (under UOPE-II ,UGC), for providing grants.

\section{References}

Altschul S.F.I., Madden T.L., Schaffer A.A., Zhang J., Zhang Z., Miller W. and Lipman D.J. (1997), Gapped BLAST and PSIBLAST: a new generation of protein database search programs, Nucleic Acids Res, 25(17), 3389-3402.

Baev M., Schklyar N., Chistoserdova L., Chistoserdov A., Polanuer B., Tsygankov Y. and Sterkin V. (1992), Growth of the obligate methylotroph Methylobacillus flagellatum under stationary and nonstationary conditions during continuous cultivation, Biotechnology and Bioengineering, 39(6), 688-695.

Bardgett R.D. and van der Putten W.H. (2014), Belowground biodiversity and ecosystem functioning, Nature, 515(7528), 505-511. doi:10.1038/nature13855

Benstead J., King G. and Williams H. (1998), Methanol promotes atmospheric methane oxidation by methanotrophic cultures and soils, Applied and Environmental Microbiology, 64(3), 1091-1098.

Bloom A.A., Palmer P.I., Fraser A., Reay D.S. and Frankenberg C. (2010), Large-scale controls of methanogenesis inferred from methane and gravity spaceborne data, Science, 327(5963), 322-325.

Bridgham S.D., Cadillo-Quiroz H., Keller J.K. and Zhuang Q. (2013), Methane emissions from wetlands: biogeochemical, microbial, and modeling perspectives from local to global scales, Global change biology, 19(5), 1325-1346.

Cai Y., Zheng Y., Bodelier P.L., Conrad R. and Jia Z. (2016) Conventional methanotrophs are responsible for atmospheric methane oxidation in paddy soils, Nature communications, $\mathbf{7}$. doi:10.1038/ncomms11728

Chen Y., Dumont M.G., Cébron A. and Murrell J.C. (2007), Identification of active methanotrophs in a landfill cover soil through detection of expression of 16S rRNA and functional genes, Environmental Microbiology, 9(11), 2855-2869.

Chistoserdova L., Lapidus A., Han C., Goodwin L., Saunders L., Brettin T., Tapia R., Gilna P., Lucas S. and Richardson P.M. (2007), Genome of Methylobacillus flagellatus, molecular basis for obligate methylotrophy, and polyphyletic origin of methylotrophy, Journal of Bacteriology, 189(11), 4020-4027.

Chu S. and Majumdar A. (2012), Opportunities and challenges for a sustainable energy future, Nature, 488(7411), 294-303.

Collins M., Knutti R., Arblaster J., Dufresne J., Fichefet T., Friedlingstein P., Gao X., Gutowski W., Johns T. and Krinner G. (2013), Contribution of working group I to the fifth assessment report of the intergovernmental panel on climate change. Climate Change

Conrado R.J. and Gonzalez R. (2014), Envisioning the bioconversion of Methane to liquid fuels, Science, 343(6171), 621-623. 
doi:10.1038/nature13164

http://www.nature.com/nature/journal/v507/n7493/abs/na ture13164.html\#supplementary-information

doi:10.1038/ngeo1955.(http://www.nature.com/ngeo/journ al/v6/n10/abs/ngeo1955.html\#supplementary-information). doi:10.1038/nrmicro.2016.32

Edenhofer, Ottmar, et al. "IPCC special report on renewable energy sources and climate change mitigation." Prepared By Working Group III of the Intergovernmental Panel on Climate Change, Cambridge University Press, Cambridge, UK (2011).

Eshinimaev B.T., Khmelenina V.N., Sakharovskii V.G., Suzina N.E. and Trotsenko Y.A. (2002), Physiological, biochemical, and cytological characteristics of a haloalkalitolerant methanotroph grown on methanol, Microbiology, 71(5), 512-518.

Gilman A., Laurens L.M., Puri A.W., Chu F., Pienkos P.T. and Lidstrom M.E. (2015), Bioreactor performance parameters for an industrially-promising methanotroph Methylomicrobium buryatense 5GB1, Microbial Cell Factories, 14(1), 182.

Gogleva A.A., Kaparullina E.N., Doronina N.V. and Trotsenko Y.A. (2011), Methylobacillus arboreus sp. nov., and Methylobacillus gramineus sp. nov., novel non-pigmented obligately methylotrophic bacteria associated with plants, Systematic and Applied Microbiology, 34(7), 477-481.

Gupta S., Choudhary N. and Alappat B.J. Bioreactor landfill for MSW Disposal in Delhi. In: Proceedings of the International Conference on Sustainable Solid Waste Management, Chennai, India, 2007: 474-481

Han B., Chen Y., Abell G., Jiang H., Bodrossy L., Zhao J., Murrell J.C. and Xing X.H. (2009), Diversity and activity of methanotrophs in alkaline soil from a Chinese coal mine, FEMS Microbiology Ecology, 70(2), 196-207.

Hansen L.B., Finster K., Fossing H. and Iversen N. (1998), Anaerobic methane oxidation in sulfate depleted sediments: effects of sulfate and molybdate additions, Aquatic Microbial Ecology, 14(2), 195-204.

Hanson R.S. and Hanson T.E. (1996), Methanotrophic bacteria, Microbiological reviews, 60(2), 439-471.

Houghton J.T., Ding Y., Griggs D.J., Noguer M., van der Linden P.J., Dai X., Maskell K. and Johnson C. (2001) Climate change 2001: the scientific basis, vol 881. Cambridge university press Cambridge,

Hu P., Chakraborty S., Kumar A., Woolston B., Liu H., Emerson D. and Stephanopoulos G. (2016), Integrated bioprocess for conversion of gaseous substrates to liquids, Proceedings of the National Academy of Sciences, 113(14), 3773-3778.

Hwang I.Y., Lee S.H., Choi Y.S., Park S.J., Na J.G., Chang I.S., Kim C., Kim H.C., Kim Y.H., Lee J.W. and Lee E.Y. (2014), Biocatalytic conversion of methane to methanol as a key step for development of methane-based biorefineries, J. Microbiol. Biotechnol., 24, 1597-1605.

Jackson R.B., Canadell J.G., Le Quéré C., Andrew R.M., Korsbakken J.I., Peters G.P. and Nakicenovic N. (2015), Reaching peak emissions. Nature Climate Change, 6(1), 7-10. doi:10.1038/nclimate2892

Kalyuzhnaya M.G., Yang S., Rozova O.N., Smalley N.E., Clubb J., Lamb A., Gowda G.A.N., Raftery D., Fu Y., Bringel F., Vuilleumier S., Beck D.A.C., Trotsenko Y.A., Khmelenina V.N. and Lidstrom M.E. (2013), Highly efficient methane biocatalysis revealed in a methanotrophic bacterium, Nat Commun, 4, doi:10.1038/ncomms3785
Kimura M. (1980), A simple method for estimating evolutionary rates of base substitutions through comparative studies of nucleotide sequences, Journal of Molecular Evolution, 16(2), 111-120.

Kirschke S., Bousquet P., Ciais P., Saunois M., Canadell J.G., Dlugokencky E.J., Bergamaschi P., Bergmann D., Blake D.R., Bruhwiler L., Cameron-Smith P., Castaldi S., Chevallier F., Feng L., Fraser A., Heimann M., Hodson E.L., Houweling S., Josse B., Fraser P.J., Krummel P.B., Lamarque J-F, Langenfelds R.L., Le Quere C., Naik V., O'Doherty S., Palmer P.I., Pison I., Plummer D., Poulter B., Prinn R.G., Rigby M., Ringeval B., Santini M., Schmidt M., Shindell D.T., Simpson I.J., Spahni R., Steele L.P., Strode S.A., Sudo K., Szopa S., van der Werf G.R., Voulgarakis A., van Weele M., Weiss R.F., Williams J.E. and Zeng G. (2013), Three decades of global methane sources and sinks, Nature Geoscience, 6(10), 813-823.

Kumar S., Bhattacharyya J., Vaidya A., Chakrabarti T., Devotta S. and Akolkar A. (2009), Assessment of the status of municipal solid waste management in metro cities, state capitals, class I cities, and class II towns in India: an insight, Waste Management, 29(2), 883-895.

Lee H.J., Jeong S.E., Kim P.J., Madsen E.L. and Jeon C.O. (2015), High resolution depth distribution of Bacteria, Archaea, methanotrophs, and methanogens in the bulk and rhizosphere soils of a flooded rice paddy, Frontiers in Microbiology, 6. doi:10.3389/fmicb.2015.00639

Liao J.C., Mi L., Pontrelli S. and Luo S. (2016), Fuelling the future: microbial engineering for the production of sustainable biofuels, Nat Rev Micro, 14(5), 288-304

Mayumi D., Dolfing J., Sakata S., Maeda H., Miyagawa Y., Ikarashi M., Tamaki H., Takeuchi M., Nakatsu C.H. and Kamagata Y. (2013), Carbon dioxide concentration dictates alternative methanogenic pathways in oil reservoirs, Nature Communications, 13(4). doi:10.1038/ncomms2998.

Murrell J.C., McDonald I.R. and Bourne D.G. (1998), Molecular methods for the study of methanotroph ecology, FEMS Microbiology Ecology, 27(2), 103-114.

Musenze R.S., Fan L., Grinham A., Werner U., Gale D., Udy J. and Yuan Z. (2016), Methane dynamics in subtropical freshwater reservoirs and the mediating microbial communities, Biogeochemistry, 128(1), 233-255. doi:10.1007/s10533-0160206-8

Nielsen J., Fussenegger M., Keasling J., Lee S.Y., Liao J.C., Prather K. and Palsson B. (2014), Engineering synergy in biotechnology, Nat Chem Biol, 10(5), 319-322. doi:10.1038/nchembio.1519

Peralta-Yahya P.P., Zhang F., del Cardayre S.B. and Keasling J.D. (2012), Microbial engineering for the production of advanced biofuels, Nature, 488(7411), 320-328.

Rawat M. and Ramanathan A. (2011), Assessment of methane flux from municipal solid waste (MSW) landfill areas of Delhi, India, Journal of Environmental Protection, 2(4).

Sathaye J., Shukla P. and Ravindranath N. (2006), Climate change, sustainable development and India: Global and national concerns, Current Science-Banglore, 90(3), 314.

Schimel J. (2000), Global change: rice, microbes and methane, Nature, 403(6768), 375-377.

Sharma S., Bhattacharya S. and Garg A. (2006), Greenhouse gas emissions from India: a perspective, Current ScienceBanglore, 90(3), 326. 
Singh J.S. (2011), Methanotrophs: the potential biological sink to mitigate the global methane load, Current Science, 100(1), 29-30.

Singh V., Mittal A. Toxicity Analysis and Public Health Aspects of Municipal Landfill Leachate: A Case Study of Okhla Landfill, Delhi. In: 8th World Wide Workshop for Young Environmental Scientists WWW-YES 2009: Urban waters: resource or risks? 2-5 June 2009, 2011.

Solomon S. (2007) Climate change 2007-the physical science basis: Working group I contribution to the fourth assessment report of the IPCC, vol 4. Cambridge University Press,

Strong P, Xie S. and Clarke W. (2015), Methane as a resource: can the methanotrophs add value?, Environmental Science and Technology, 49(7), 4001-4018.

Su Y., Zhang X., Xia F-F, Zhang Q-Q, Kong J-Y, Wang J. and He R. (2014), Diversity and activity of methanotrophs in landfill cover soils with and without landfill gas recovery systems, Systematic and Applied Microbiology, 37(3), 200-207.

Talyan V., Dahiya R. and Sreekrishnan T. (2008), State of municipal solid waste management in Delhi, the capital of India, Waste Management, 28(7), 1276-1287.

Talyan V., Dahiya R., Anand S. and Sreekrishnan T. (2007), Quantification of methane emission from municipal solid waste disposal in Delhi, Resources, conservation and recycling, 50(3), 240-259.

Tamura K., Stecher G., Peterson D., Filipski A. and Kumar S. (2013), MEGA6: Molecular Evolutionary Genetics Analysis Version 6.0., Molecular biology and evolution, 30(12), 2725-2729.

Yadav S., Kundu S., Ghosh S.K. and Maitra S. (2015), Molecular analysis of methanogen richness in landfill and marshland targeting 16S rDNA sequences. Archaea (2015):1-9. Article ID 563414, http://dx.doi.org/10.1155/2015/563414

Yadav S., Maitra S., Pal S., Singh N., Gupta S., Ghosh S. and Sreekishnan T. (2014), Accumulation of Lactic acid during biodigestion of municipal solid waste leachate and Identification of Indigenous Lactic Acid Bacteria in leachate, Journal of Hazardous, Toxic, and Radioactive Waste, 18(4), 04014021.

Yvon-Durocher G., Allen A.P., Bastviken D., Conrad R., Gudasz C., St-Pierre A., Thanh-Duc N. and del Giorgio P.A. (2014), Methane fluxes show consistent temperature dependence across microbial to ecosystem scales, Nature, 507(7493), 488-491. 